\title{
Scalp vascularization as a marker of topical minoxidil treatment efficacy in patients with androgenetic alopecia
}

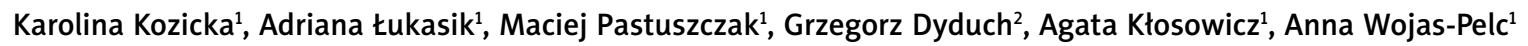 \\ ${ }^{1}$ Department of Dermatology, Jagiellonian University Medical College, Krakow, Poland \\ ${ }^{2}$ Department of Pathomorphology, Jagiellonian University Medical College, Krakow, Poland \\ Adv Dermatol Allergol 2022; XXXIX (2): 316-320 \\ DOI: https://doi.org/10.5114/ada.2021.103301
}

\begin{abstract}
Introduction: Androgenetic alopecia is the most common type of non-cicatricial hair loss both in male and female patients. The pathomechanism of the disease involves chronic and progressive miniaturization of hair follicles, which leads to the conversion of terminal hair to vellus hair. Minoxidil is a first-line drug in the treatment of female pattern hair loss (FPHL).

Aim: The study is aimed at verifying whether the degree of scalp vascularization has an impact on the efficacy of topical $5 \%$ minoxidil treatment.

Material and methods: The study involved a group of 76 patients diagnosed with FPHL, who underwent a scalp biopsy for a histological examination of their scalp vascularization. The patients were divided into two groups, with rich and poor scalp vasculature. In all patients, topical treatment with $5 \%$ minoxidil was applied for a minimum of 6 months, followed by video-trichoscopic assessment.

Results: A significant increase in the total count was observed 6 months into the treatment as compared with baseline, and a decrease in the number of single hair per follicle. It was observed that the number of single hair units had gone down in $50.67 \%$ of patients. The study also demonstrated an increase in the total hair count in $57.33 \%$ of patients as well as no drops in the total count in $68 \%$ of patients, following 6 months of treatment.

Conclusions: Patients responded equally well to the applied topical minoxidil treatment, irrespectively of the number of blood vessels in the scalp.

Key words: female pattern hair loss, minoxidil, video trichoscopy, hair disorder.
\end{abstract}

\section{Introduction}

Androgenetic alopecia is the most common type of non-cicatricial hair loss both in male and female patients [1]. The pathomechanism of the disease involves chronic and progressive miniaturization of hair follicles, which leads to the conversion of terminal hair to vellus hair [2]. Patients who remain without treatment manifest a continuous progression of the disease. The incidence of the condition goes up with age. In women before the age of 30 , female pattern hair loss (FPHL) is present in $3-6 \%$ of the population, going up to as much as $30-40 \%$ in the $50+$ population, constituting a health problem as well as a psychological and social ailment. The aetiology of the condition is not fully known. A genetic background to the disease is postulated [3]. Food and Drug Administration (FDA)-registered drugs in the treatment of androgenetic alopecia (AGA) include topical minoxidil and systemic finasteride in males as well as low laser light therapy [4, 5].
Minoxidil is a pyrimidine derivative with hypotensive qualities. Its exact mechanism of action is not yet known. It is proposed that it stimulates local hair growth by increasing blood flow through the skin's vascular bed, causing vasodilation and proliferation of blood vessels surrounding hair follicles [6], and leading to an increase in vascular endothelial growth factor (VEGF) levels [7]. It results in shortening of the telogen phase, prolongation of the anagen phase, and production of a longer hair. The initial effects, involving an increased number of vellus hair, and inhibition of hair loss, should be observed 2 months into the treatment. Most sources indicate a 6-month treatment period that leads to the full effect. In a study carried out by Goren et al., only $40 \%$ of patients who had been applying minoxidil for 16 weeks responded to the therapy with hair growth [8]. Other studies have demonstrated improvement in $40 \%$ of patients 6 months into the treatment [9]. Some of the patients fail

Address for correspondence: Karolina Kozicka, Department of Dermatology, Jagiellonian University Medical College, 50 Kopernika St, 31-501 Krakow, Poland, e-mail: drkarolinakozicka@gmail.com Received: 30.11 .2020 , accepted: 11.01 .2021$. 
to respond to topical minoxidil therapy, with predictive factors remaining unknown to date.

Minoxidil is available as $2 \%$ and $5 \%$ solutions. Adverse events include telogen effluvium hair loss (6-8 weeks from the beginning of treatment), which recedes over the period of several weeks, facial hypertrichosis (after the $5 \%$ minoxidil solution), scalp irritation and pruritus, headache, vertigo and tachycardia. Minoxidil should not be used during pregnancy and lactation. Minoxidil is a pro-drug that is converted by the sulfotransferase enzyme to its active form of minoxidil sulfatase in the outer sheath of the hair follicle. Minoxidil sulfatase is an active metabolite that stimulates fair follicles [8].

Trichoscopy is a valuable and dynamically developing method, which serves to diagnose as well as monitor the treatment of alopecia. With the help of video dermatoscopy, one may register and compare scalp images taken throughout the treatment. The method is used more and more frequently in the diagnostics of the vascular structure in the superficial layers of the dermis.

The CD31 antibody was used as an immunohistochemical marker which enables the assessment of cutaneous vascularization.

\section{Aim}

Taking into account minoxidil's mechanism of action that primarily impacts the vascular bed surrounding hair follicles, this study aims to assess the vascularization of scalp areas that are affected by androgenetic alopecia, and to search for a correlation between the extent of vascularization and response to minoxidil therapy.

\section{Material and methods}

Seventy-six patients with diagnosed FPHL underwent scalp biopsy (parietal region) for a histological assessment of scalp vascularization (based on the expression of CD31 in the examined tissue material). Patients were divided into two groups: with rich and poor scalp vasculature. Rich scalp vasculature was defined as the blood vessel count exceeding the median value for the study population, i.e. more than 60 vessels per $\mathrm{cm}^{2}$, whereas poor vascularization was defined as the blood vessel count of 60 vessels per $\mathrm{cm}^{2}$ or less.

All patients were started on topical $5 \%$ minoxidil, applied once daily for a minimum of 6 months, followed by assessment and video-trichoscopic imaging, with another follow-up examination scheduled 9 to 24 months into the treatment. Patients were monitored with video trichoscopy. The working assumption was that patients with rich scalp vascularization would have better treatment results. Trichoscopic images were taken with the use of Medicam 800 video dermatoscope produced by FotoFinder (Bad Birnbach, Germany). Trichoscopy images were analysed at the TrichoLAB laboratory (Warsaw,
Poland). The following parameters were assessed: average hair count per $\mathrm{cm}^{2}$ (total count), average hair thickness, percentage share of hair $<30 \mu \mathrm{m}$ (first group thickness), percentage share of hair sized 30-50 $\mu \mathrm{m}$ (second group thickness), percentage share of hair $>50 \mu \mathrm{m}$ (third group thickness), percentage share of single hair per follicle (single unit), percentage share of double hair in follicle (double unit), percentage share of triple hair in follicle (triple unit), cumulative hair thickness per $\mathrm{cm}^{2}$ (cumulative hair thickness density), and follicular unit density per $\mathrm{cm}^{2}$ (FU density) [10].

Improvement was defined as an increase in the values of the following parameters: total count, average thickness, second and third group thickness, double unit, triple unit, cumulative hair thickness density, and FU density. Improvement was also demonstrated as a decrease in the percentage values of the following parameters: single unit, and first group thickness. Inclusion criteria included clinical features (based on the 3-stage Ludwig scale, and on the 5-stage Sinclair scale) as well as dermatoscopic (trichoscopic) and histological signs of androgenetic alopecia. An exclusion criterion was another cause of hair loss, e.g. hypothyroidism, anaemia, etc. The use of an additional form of systemic treatment, e.g. with spironolactone or finasteride, was also an exclusion criterion. All patients gave their written consent for the biopsy procedure for the purpose of histological examination. The Jagiellonian University Bioethics Committee approved the procedure. The number of the approval: 1072.6120.24.2019.

\section{Statistical analysis}

Normality of quantitative variable distribution was analysed with the Shapiro-Wilk test. Variables with distribution other than normal were presented as medians and first and third quartiles (Q1-Q3). Qualitative variables were presented as percentages. Comparative analysis was performed with the use of Pearson's $\chi^{2}$ test for categorical data, and with the use of the MannWhitney $U$ test for non-normally distributed continuous variables. Response to treatment was assessed with the use of repeated measures analysis of variance. In cases of statistical significance, post-hoc Scheffe tests were performed. The level of statistical significance was set at $p<0.05$.

All calculations were performed using Statistica version 13 software (2017; TIBCO Software Inc.).

\section{Results}

The average age of study participants was 49. The median duration of hair loss was 4 years (Q1-Q3: 1-10 years).

Without dividing patients into groups, a significant increase in the total count was observed 6 months into the treatment as compared to the baseline visit (Figure 1), 


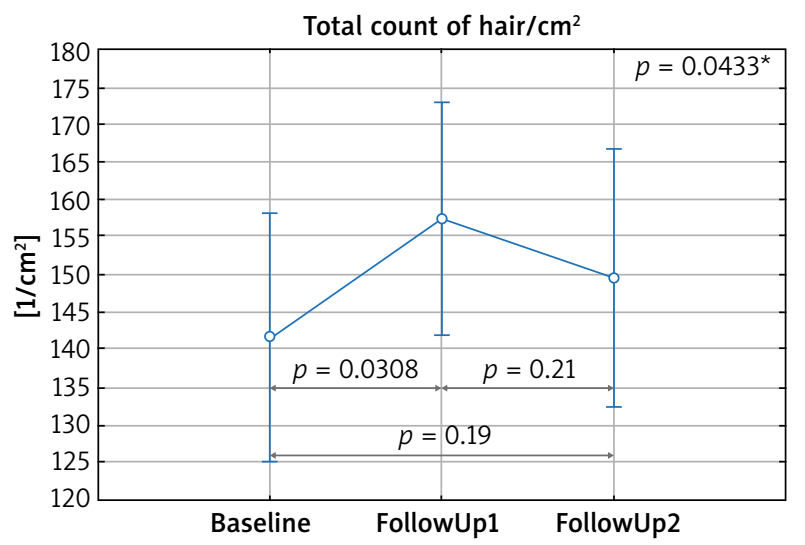

Figure 1. Average hair count per $\mathrm{cm}^{2}$ (total count) depending on the time of measurement. Baseline - first visit, FollowUp1 - visit after 6 months, FollowUp2 - visit after 9-24 months from the baseline. ${ }^{*}$ In the post-hoc test a statistically significant difference between Baseline and FollowUp1 was demonstrated

and a decrease in the number of single hair per follicle as compared to baseline (Figure 2).

A decrease in the number of single follicular units was observed in $50.67 \%$ of patients. No decrease in the total hair count was reported for $68 \%$ of patients, out of which $84.30 \%$ of patients experienced additional hair growth.

Based on the histological examination, and measurement of the number of vessels in the scalp with the use of the CD31 antibody, patients were divided into two groups. $44 \%$ of patients were included in the rich vascularization group, and the remaining ones were qualified as those with poor scalp vascularization.

When divided into different scalp vascularization groups, patients with rich scalp vascularization and those with poor scalp vasculature responded equally well to the topical treatment with minoxidil.

With respect to other comparable parameters, including hair thickness, density of follicular units, percentage share of single, double and triple units, cumulative hair thickness density, and percentage shares of differentthickness hair, no statistically significant differences were observed.

Patients who initiated their treatment earlier (up to 4 years from diagnosis) benefitted more from treatment (Table 1).

Based on our study results, patients who were followed up on for more than 6 months (9-24 months) from their baseline visit failed to show further improvement with respect to the parameters under assessment.

\section{Discussion}

In 1988, FDA registered Minoxidil for topical treatment of androgenetic alopecia in the United States [6].

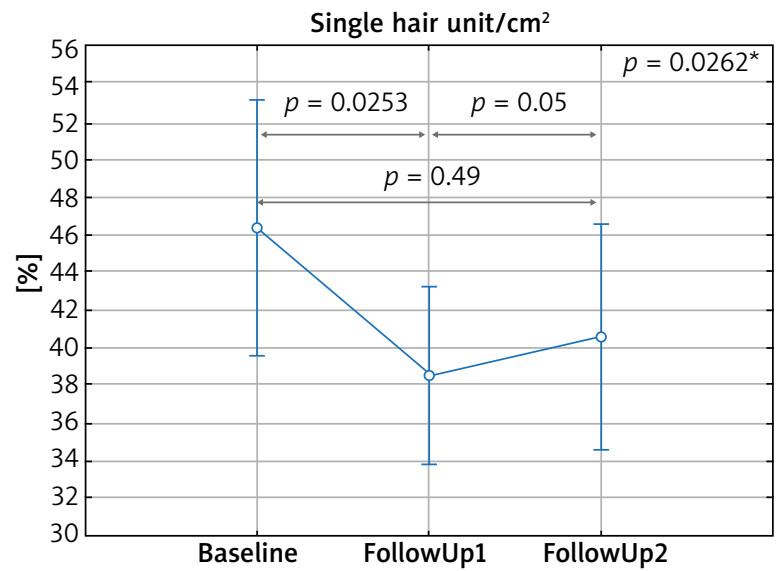

Figure 2. Percentage share of single hair per follicle (single unit) depending on the time of measurement. Baseline first visit, FollowUp1 - visit after 6 months, FollowUp2 visit after 9-24 months from the baseline. *In the post-hoc test a statistically significant difference between Baseline and FollowUp1 was demonstrated

At that time, the $2 \%$ minoxidil formula was only registered for male patients. Presently, minoxidil is available as an over-the-counter product in the form of $2 \%$ and 5\% solutions, and a 5\% minoxidil foam (not available in Poland) both for men and women. Therapeutic results are observed up to 6 months into the treatment. Its efficacy has been proven, and the drug has a good safety profile, with minimum side effects [6, 11, 12]. Minoxidil improves blood flow through the scalp [13], and activates potassium channels, which stimulates the transition of hair follicles from the telogen phase to the anagen phase [14]. Side effects include facial hypertrichosis, contact dermatitis on the scalp, and pruritus of the scalp, resulting from the presence of propylene glycol in the minoxidil solution. Telogen hair loss may occur in the first month of treatment $[15,16]$.

Minoxidil is considered as first-line treatment in androgenetic alopecia. The $2 \%$ preparation is applied twice daily, and the $5 \%$ solution is applied once daily [6]. In a study carried out by Katzer et al., it was indicated that $89 \%$ of patients receive it at their first appointment [5].

According to the relevant literature, ca. $40 \%$ of patients experience improvement following topical treatment, and systemic therapy is applied in the remaining patients.

Drawing on the vascular dilation effect, the present study works on the hypothesis that patients who have richer scalp vascularization will benefit more from topical treatment than those with poorer scalp vascularization. The conducted assessments, however, refuted the above-mentioned thesis. Improvement with respect to the total hair count parameter in the studied parietal area, and with respect to the decrease in the number of single follicular units, failed to demonstrate statistically significant differences between the two study arms. Per- 
Table 1. Comparison of the results of repeated measures analysis depending on the disease duration

\begin{tabular}{|c|c|c|c|c|c|c|c|}
\hline \multirow[t]{2}{*}{ Parameter } & \multicolumn{2}{|c|}{ Baseline } & \multicolumn{2}{|c|}{ FollowUp1 } & \multicolumn{2}{|c|}{ FollowUp2 } & \multirow[t]{2}{*}{$P$-value } \\
\hline & $\begin{array}{l}\text { Up to } 4 \text { years } \\
\text { from diagnosis }\end{array}$ & $\begin{array}{c}>4 \text { years } \\
\text { from } \\
\text { diagnosis }\end{array}$ & $\begin{array}{l}\text { Up to } 4 \text { years } \\
\text { from diagnosis }\end{array}$ & $\begin{array}{c}>4 \text { years } \\
\text { from diagnosis }\end{array}$ & $\begin{array}{l}\text { Up to } 4 \text { years } \\
\text { from diagnosis }\end{array}$ & $\begin{array}{c}>4 \text { years } \\
\text { from } \\
\text { diagnosis }\end{array}$ & \\
\hline $\begin{array}{l}\text { Total count }\left[1 / \mathrm{cm}^{2}\right] \\
\text { (Q1-Q3) }\end{array}$ & $\begin{array}{c}159 \\
(122.00-193.00)\end{array}$ & $\begin{array}{c}126 \\
(88.00-151.00)\end{array}$ & $\begin{array}{c}172 \\
(130.00-210.00)\end{array}$ & $\begin{array}{c}134 \\
(105.00-155.00)\end{array}$ & $\begin{array}{c}132 \\
(113.00-176.00)\end{array}$ & $\begin{array}{c}147 \\
(117.00-180.00)\end{array}$ & 0.026 \\
\hline $\begin{array}{l}\text { Average thickness } \\
{[\mu \mathrm{m}](\mathrm{Q} 1-\mathrm{Q} 3)}\end{array}$ & $\begin{array}{c}55.12 \\
(50.14-60.98) \\
\end{array}$ & $\begin{array}{c}56.70 \\
(51.84-60.69) \\
\end{array}$ & $\begin{array}{c}60.25 \\
(49.06-65.01) \\
\end{array}$ & $\begin{array}{c}57.23 \\
(53.40-65.44) \\
\end{array}$ & $\begin{array}{c}57.64 \\
(52.56-64.16) \\
\end{array}$ & $\begin{array}{c}57.70 \\
(51.22-61.49) \\
\end{array}$ & 0.53 \\
\hline $\begin{array}{l}\text { Thickness } 1^{\text {st }} \text { gr (\%) } \\
\text { (Q1-Q3) }\end{array}$ & $\begin{array}{c}3.33 \\
(1.47-7.14)\end{array}$ & $\begin{array}{c}3.03 \\
(0-6.67) \\
\end{array}$ & $\begin{array}{l}3.23 \\
(0-8) \\
\end{array}$ & $\begin{array}{c}2.38 \\
(0-4.44)\end{array}$ & $\begin{array}{c}1.11 \\
(0-5.41) \\
\end{array}$ & $\begin{array}{c}4.76 \\
(0-9.76)\end{array}$ & 0.89 \\
\hline $\begin{array}{l}\text { Thickness } 2^{\text {nd }} \text { gr (\%) } \\
\text { (Q1-Q3) }\end{array}$ & $\begin{array}{c}29.73 \\
(18.75-42.86)\end{array}$ & $\begin{array}{c}29.63 \\
(23.53-34.78)\end{array}$ & $\begin{array}{c}26.47 \\
(13.89-47.62)\end{array}$ & $\begin{array}{c}30.56 \\
(18.52-44.00)\end{array}$ & $\begin{array}{c}25.53 \\
(15.56-33.33)\end{array}$ & $\begin{array}{c}34.55 \\
(25.00-38.24)\end{array}$ & 0.59 \\
\hline $\begin{array}{l}\text { Thickness 3 } 3^{\text {rd }} \text { gr (\%) } \\
\text { (Q1-Q3) }\end{array}$ & $\begin{array}{c}65.91 \\
(50.00-78.79)\end{array}$ & $\begin{array}{c}66.67 \\
(52.94-75.00) \\
\end{array}$ & $\begin{array}{c}69.23 \\
(47.62-84.00)\end{array}$ & $\begin{array}{c}64.71 \\
(50.00-81.48) \\
\end{array}$ & $\begin{array}{c}73.62 \\
(56.67-82.22)\end{array}$ & $\begin{array}{c}61.76 \\
(51.06-75.00)\end{array}$ & 0.56 \\
\hline $\begin{array}{l}\text { Single unit (\%) } \\
\text { (Q1-Q3) }\end{array}$ & $\begin{array}{c}37.04 \\
(27.78-55.00)\end{array}$ & $\begin{array}{c}52.63 \\
(31.82-66.67) \\
\end{array}$ & $\begin{array}{c}37.50 \\
(27.27-45.45) \\
\end{array}$ & $\begin{array}{c}40.91 \\
(34.78-61.11)\end{array}$ & $\begin{array}{c}42.68 \\
(25.00-55.56) \\
\end{array}$ & $\begin{array}{c}38.89 \\
(27.78-52.63)\end{array}$ & 0.64 \\
\hline $\begin{array}{l}\text { Double unit (\%) } \\
\text { (Q1-Q3) }\end{array}$ & $\begin{array}{c}35 \\
(28.57-42.86)\end{array}$ & $\begin{array}{c}33.33 \\
(20.00-47.37)\end{array}$ & $\begin{array}{c}36.36 \\
(31.58-43.33)\end{array}$ & $\begin{array}{c}38.10 \\
(27.78-50.00)\end{array}$ & $\begin{array}{c}37.87 \\
(29.41-50.00)\end{array}$ & $\begin{array}{c}41.67 \\
(30.77-47.62)\end{array}$ & 0.92 \\
\hline $\begin{array}{l}\text { Triple unit (\%) } \\
\text { (Q1-Q3) }\end{array}$ & $\begin{array}{c}23.81 \\
(10.53-34.78) \\
\end{array}$ & $\begin{array}{c}11.11 \\
(6.67-22.22)\end{array}$ & $\begin{array}{c}27.27 \\
(11.11-35.29) \\
\end{array}$ & $\begin{array}{l}13.64(6.67- \\
22.22)\end{array}$ & $\begin{array}{c}18.61 \\
(11.76-26.32) \\
\end{array}$ & $\begin{array}{c}22.22 \\
(13.04-28.57) \\
\end{array}$ & 0.20 \\
\hline $\begin{array}{l}\text { Cum hair thick dens } \\
{\left[\mu \mathrm{m} / \mathrm{cm}^{2}\right](\mathrm{Q} 1-\mathrm{Q} 3)}\end{array}$ & $\begin{array}{c}8.70 \mid(7.19- \\
11.47)\end{array}$ & $\begin{array}{c}7.28 \\
(4.98-8.44) \\
\end{array}$ & $\begin{array}{c}10.04 \\
(6.99-12.57)\end{array}$ & $\begin{array}{c}7.99 \\
(5.68-9.07) \\
\end{array}$ & $\begin{array}{c}8.09 \\
(6.05-10.27) \\
\end{array}$ & $\begin{array}{c}8.35 \\
(7.18-10.10)\end{array}$ & 0.0102 \\
\hline $\begin{array}{l}\text { FU dens }\left[1 / \mathrm{cm}^{2}\right] \\
\text { (Q1-Q3) }\end{array}$ & $\begin{array}{c}88.05 \\
(71.27-96.43)\end{array}$ & $\begin{array}{c}75.47 \\
(62.89-83.85)\end{array}$ & $\begin{array}{c}88.05 \\
(75.47-100.62)\end{array}$ & $\begin{array}{c}75.47 \\
(62.89-83.85)\end{array}$ & $\begin{array}{l}79.66(71.27- \\
83.85)\end{array}$ & $\begin{array}{c}79.66 \\
(75.47-88.05)\end{array}$ & $0.0442^{\#}$ \\
\hline
\end{tabular}

\#No statistically significant differences observed in the post-hoc tests, Total count - average hair count per $\mathrm{cm}^{2}$, average hair thickness, first group thickness -

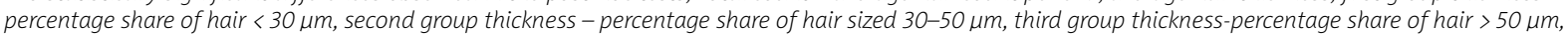
single unit - percentage share of single hair per follicle, double unit - percentage share of double hair in follicle, triple unit - percentage share of triple hair in follicle, cumulative hair thickness density - cumulative hair thickness per $\mathrm{cm}^{2}$, and FU density - follicular unit density per $\mathrm{cm}^{2}$.

haps the reason behind the observed results is the fact that minoxidil's mechanism of action is independent of the extent of scalp vascularization.

It may, however, be related to vasculature in a different way, i.e. it might be found to stimulate the formation of new blood vessels in patients with poorer vascularization at baseline, and thus improve their scalp blood supply, which was not analysed in this study, though.

One should also remember about several limitations of the study. A relatively small group of patients was subjected to assessment. Treatment efficacy assessment based on video trichoscopy also comes with some downsides, e.g. related to the accuracy of repeated measurements in the same location. Patient compliance is also an issue as the amounts of the drug applied by different patients are not always comparable.

The goal of the treatment applied was to inhibit hair loss, and accomplish gradual hair growth. In 68\% of patients hair loss stopped 6 months into the treatment, while in $57.33 \%$ of patients, there was additional hair growth after 6 months of regular minoxidil use. Follow-up that went beyond the 6-month period showed no further improvement, but the achieved results were maintained. The above-mentioned treatment appears to be well grounded, irrespective of the extent of scalp vascularization.

In the studies carried out to date, it has been proven that the efficacy of minoxidil therapy is correlated with the patient's age as well as with the duration of the disease [5]. Our study confirms the previous findings, thus reflecting clinical observations too, that patients whose treatment is aimed at inhibition of hair loss benefit more from minoxidil therapy than patients whose therapy is targeted at an additional stimulation of hair growth [9].

The video trichoscopy method used to monitor treatment results is ever more frequently applied in the diagnostics and monitoring of hair loss. It is a non-invasive technique, which replaces trichogram assessment, and makes it possible to minimize the number of skin biopsies (Figures 3-5).

\section{Conclusions}

Minoxidil is equally efficacious in patients with rich and poor scalp vascularization. Its efficacy was proven 6 months into the treatment. No significant further effects were observed, though, in the period of 6-24 months into the treatment. According to the present 


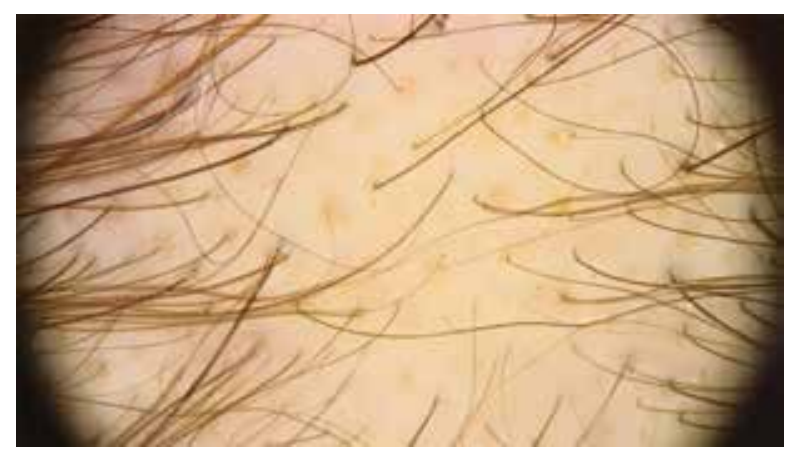

Figure 3. The patient before minoxidil treatment

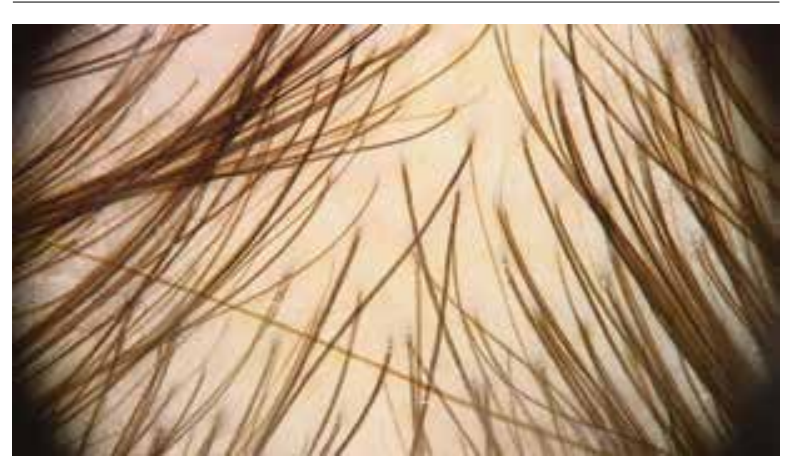

Figure 5. The same patient after 12 months of treatment

study, minoxidil helps accomplish the desired therapeutic outcome after a 6-month-long therapy, with longer treatment bringing no further benefits, but shown to maintain the previous therapeutic effect. The efficacy of minoxidil was demonstrated in patients irrespectively of the duration of the clinical symptoms.

\section{Conflict of interest}

The authors declare no conflict of interest.

\section{References}

1. Brzezińska-Wcisło L, Rakowska A, Rudnicka L, et al. Androgenetic alopecia. Diagnostic and therapeutic recommendations of the Polish Dermatological Society. Dermatol Rev/ Przegl Dermatol 2018; 105: 1-18.

2. Lolli F, Pallotti F, Rossi A, et al. Androgenetic alopecia: a review. Endocrine 2017; 57: 9-17.

3. Starace M, Orlando G, Alessandrini A. Female androgenetic alopecia: an update on diagnosis and management. Am J Clin Dermatol 2020; 21: 69-84.

4. Adil A, Godwin M. The effectiveness of treatments for androgenetic alopecia: a systematic review and meta-analysis. J Am Acad Dermatol 2017; 77: 136-141.e5.

5. Katzer T, Leite Junior A, Beck R. Physiopathology and current treatments of androgenetic alopecia: going beyond androgens and anti-androgens. Dermatol Ther 2019; 32: e13059.

6. Stoehr JR, Choi JN, Colavincenzo M. Off-label use of topical minoxidil in alopecia: a review. Am J Clin Dermatol 2019; 20: 237-50.

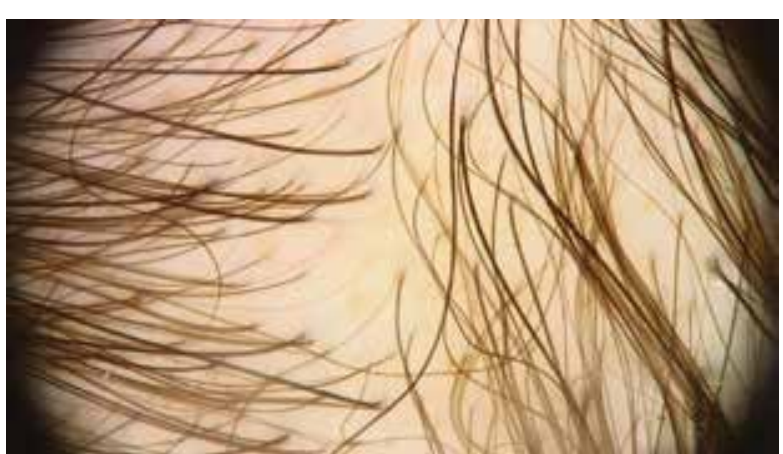

Figure 4. The same patient after 6 months of regular minoxidil treatment

7. Kelly Y, Blanco A, Tosti A. Androgenetic alopecia: an update of treatment options. Drugs 2016; 76: 1349-64.

8. Goren A, Naccarato T. Minoxidil in the treatment of androgenetic alopecia. Dermatol Ther 2018; 31: e12686.

9. Fabbrocini G, Cantelli M, Masarà A, et al. Female pattern hair loss: a clinical, pathophysiologic, and therapeutic review. Int J Womens Dermatol 2018; 4: 203-211.

10. Rakowska A. Trichoscopy (hair and scalp videodermoscopy) in the healthy female. Method standardization and norms for measurable parameters. I Dermatol Case Rep 2009; 3: 14-9.

11. Suchonwanit $P$, Thammarucha S, Leerunyakul K. Minoxidil and its use in hair disorders: a review. Drug Des Devel Ther 2019; 13: 2777-86. Erratum in: Drug Des Devel Ther 2020; 14: 575.

12. Sung CT, Juhasz ML, Choi FD, et al. The efficacy of topical minoxidil for non-scarring alopecia: a systematic review. J Drugs Dermatol 2019; 18: 155-60.

13. Wester RC, Maibach HI, Guy RH, et al. Minoxidil stimulates cutaneus blood flow in human balding scalps: pharmacodynamics measured by laser Doppler velocimetry and photopulse plethysmography. J Invest Dermatol 1984; 82: 515-7.

14. Messenger AG, Rundegren J. Minoxidil: mechanisms of action on hair growth. Br J Dermatol 2004; 150: 186-94.

15. Lucky AW, Piacquadio DJ, Ditre CM, et al. A randomized, placebo-controlled trial of $5 \%$ and $2 \%$ topical minoxidil solutions in the treatment of female pattern hair loss. J Am Acad Dermatol 2004; 50: 541-53.

16. Gupta AK, Foley KA. 5\% Minoxidil: treatment for female pattern hair loss. Skin Therapy Lett 2014; 19: 5-7. 